\title{
Retraction Note to: Coordinated response of sulfate transport, cysteine biosynthesis, and glutathione-mediated antioxidant defense in lentil (Lens culinaris Medik.) genotypes exposed to arsenic
}

\author{
Dibyendu Talukdar ${ }^{1}$ - Tulika Talukdar ${ }^{2}$
}

Published online: 5 January 2017

(C) Springer-Verlag Wien 2017

Retraction Note to: Protoplasma (2014) 251:839-855

DOI 10.1007/s00709-013-0586-8

This paper is withdrawn by the Editor in Chief due to data manipulation. Several lanes and bands of the majority of the gel figures shown in this publication where manipulated by duplicating single lanes or bands. The corresponding author agrees to the retraction.

The online version of the original article can be found at http://dx.doi. org/10.1007/s00709-013-0586-8.

Dibyendu Talukdar

dibyendutalukdar9@gmail.com

1 Plant Cell and Stress Biology Lab, Department of Botany, R.P.M. College, University of Calcutta, Uttarpara 712258, West Bengal, India

2 Department of Botany, Krishnagar Govt. College, University of Kalyani, Krishnanagar, Nadia, West Bengal, India 